\title{
39 incunables de la Bibliothèque provinciale des franciscains d'Aquitaine
}

Madeleine Zeller

\section{(2) OpenEdition}

1 Journals

Édition électronique

URL : http://journals.openedition.org/rbnu/737

DOI : 10.4000/rbnu.737

ISSN : 2679-6104

Éditeur

Bibliothèque nationale et universitaire de Strasbourg

\section{Édition imprimée}

Date de publication : 1 novembre 2018

Pagination : 101

ISBN : 9782859230784

ISSN : 2109-2761

\section{Référence électronique}

Madeleine Zeller, « 39 incunables de la Bibliothèque provinciale des franciscains d'Aquitaine », La Revue de la BNU [En ligne], 18 | 2018, mis en ligne le 01 juillet 2019, consulté le 11 décembre 2020 URL : http://journals.openedition.org/rbnu/737 ; DOI : https://doi.org/10.4000/rbnu.737

\section{(c) (i) (8)}

La Revue de la BNU est mise à disposition selon les termes de la Licence Creative Commons Attribution - Pas d'Utilisation Commerciale - Partage dans les Mêmes Conditions 4.0 International. 


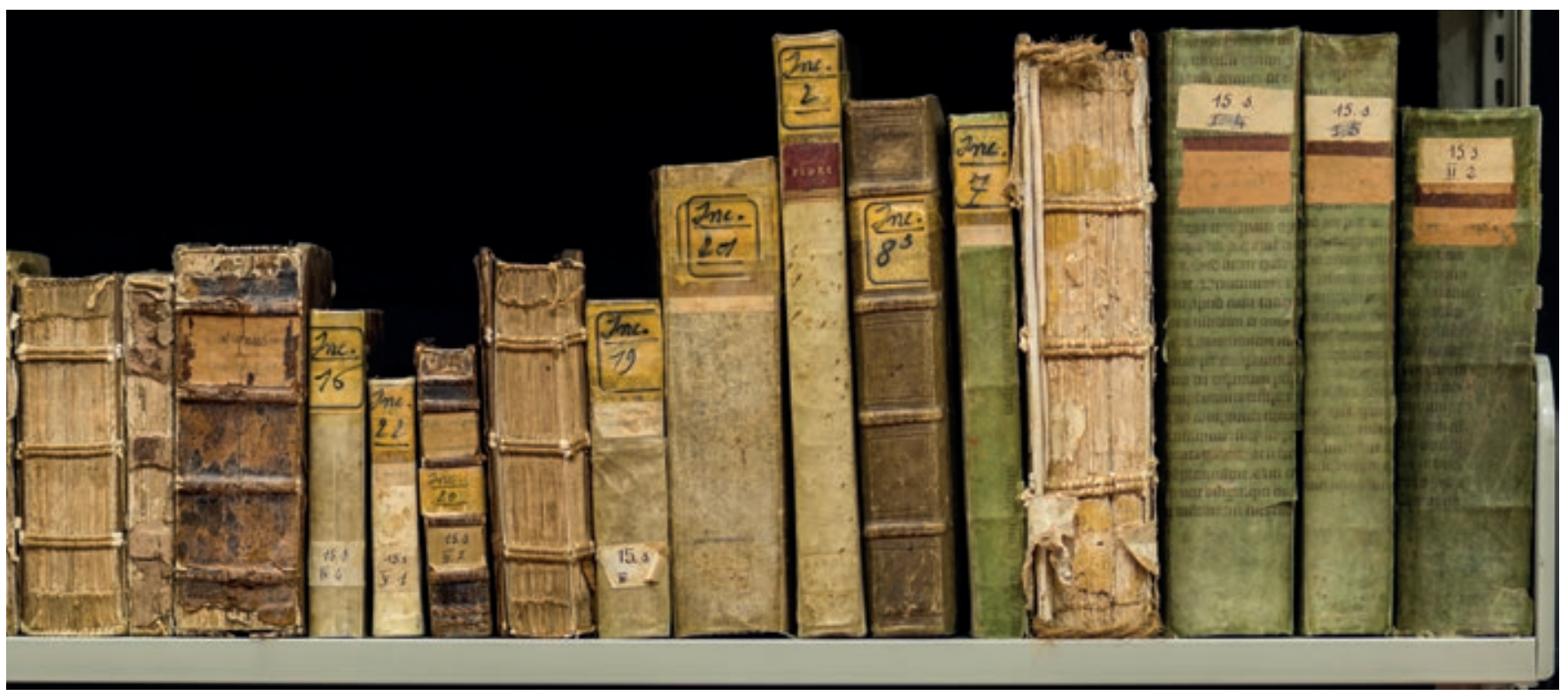

39 incunables de la

Bibliothèque provinciale des franciscains d'Aquitaine

Le fonds franciscain de la BNU s'est enrichi récemment de 400 livres patrimoniaux, conservés jusqu'alors à la Bibliothèque provinciale des franciscains d'Aquitaine à Toulouse. Cette collection compte pas moins de 39 incunables ${ }^{1}$. Il s'agit d'œuvres d'auteurs franciscains et d'autres religieux actifs du $12^{\mathrm{e}}$ au $15^{\mathrm{e}}$ siècle, imprimées durant le dernier quart du $15^{\mathrm{e}}$ siècle dans les villes de Bâle, Ferrare, Genève, Lyon, Milan, Nuremberg, Paris, Venise et Vienne (Dauphiné).

Parmi ces trésors figurent les quatre grands volumes de la Summa theologica d'Alexandre de Halès, imprimés entre 1481 et 1482 à Nuremberg par Anton Koberger, qui dirigeait alors un atelier d'imprimerie particulièrement prestigieux. La magistrale lettrine « $Q$ » qui orne le premier volume est caractéristique de la technique des incunables puisqu'elle est manuscrite et magnifiquement décorée d'une étoile à l'encre rouge.
Autre curiosité, les Quaestiones in quattuor libros sententiarum, un commentaire des célèbres Sentences de Pierre Lombard par Jean Duns Scot, « frère mineur, docteur très subtil et prince de tous les théologiens ", comme il est présenté dans l'incipit. Notre exemplaire (Venise, 1471) présente d'intéressantes annotations manuscrites en marge, dont une main pointant vers un passage précis.

Le fonds comprend également un ensemble significatif de recueils de sermons, comme cet élégant volume d'Hermannus de Petra imprimé à Lyon vers 1488 avec son poisson malicieux à l'encre rouge jouxtant une lettrine « $\mathrm{A}$ », ou encore les éditions contemporaines d'Antoine de Bitonto, Jacques de Voragine et Bernard de Clairvaux. Citons encore la prestigieuse édition du Décret de Gratien imprimée par Johann Froben (Bâle, 1493), qui s'ouvre sur un poème dédicatoire de Sebastian Brant surmonté d'une gravure composée avec soin. Cet ensemble de 39 incunables, remarquable tant par sa qualité bibliophilique que par sa cohérence intellectuelle, constitue un témoin représentatif de la production religieuse imprimée à la fin $\mathrm{du} 15^{\mathrm{e}}$ siècle. Il complète de façon significative les collections de la BNU.

\section{Madeleine Zeller}

NOTE

1- Ouvrages imprimés avant le premier janvier 1501. Les 39 incunables représentent seulement 27 volumes physiques, en raison des nombreux recueils factices réunissant plusieurs titres en un seul volume. 


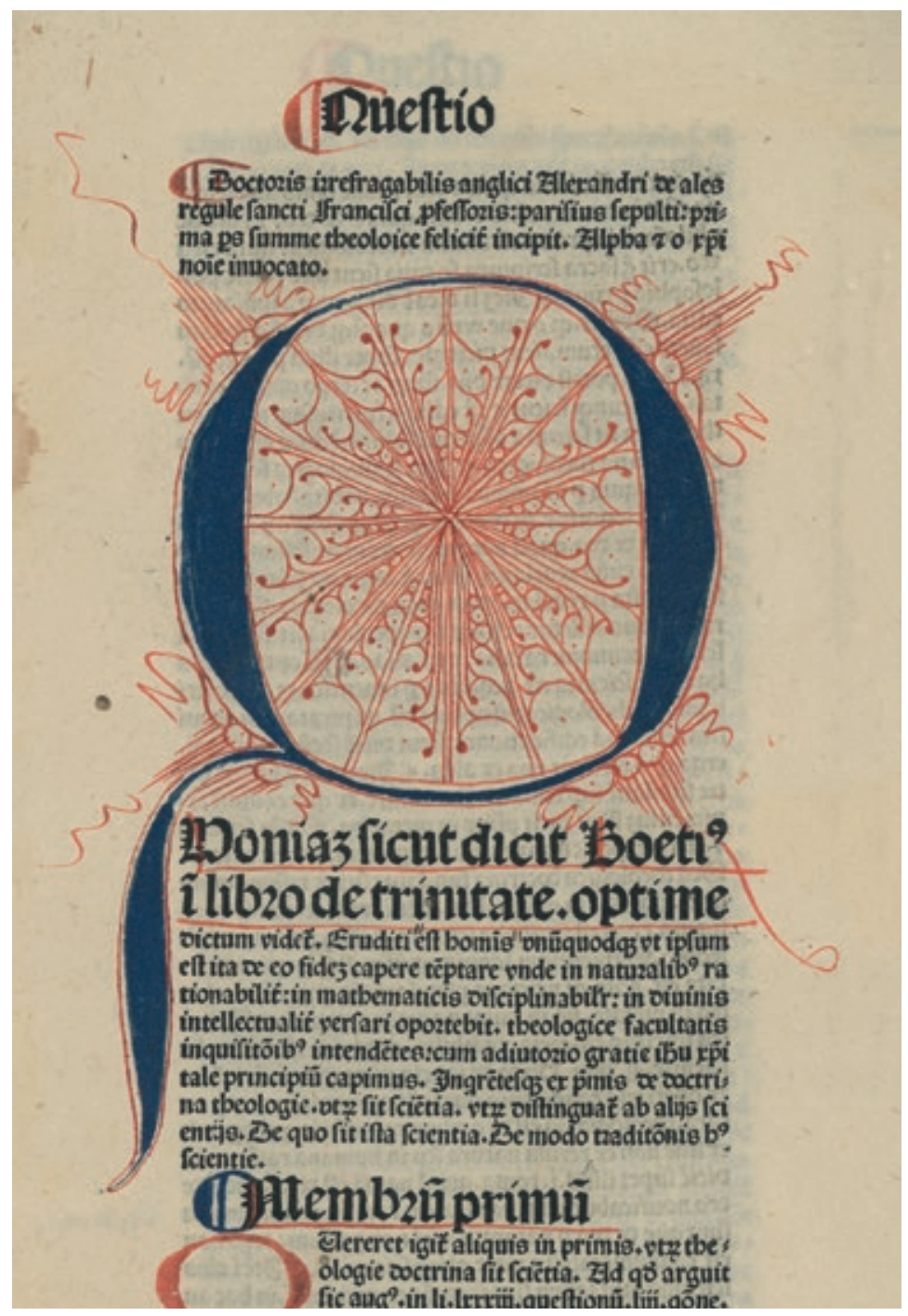

Alexandre de Halès, Summa theologica,

Nuremberg, Anton Koberger, 1481-1482

Lettrine manuscrite « $Q$ » («Quaestiones »)

au début du premier volume.

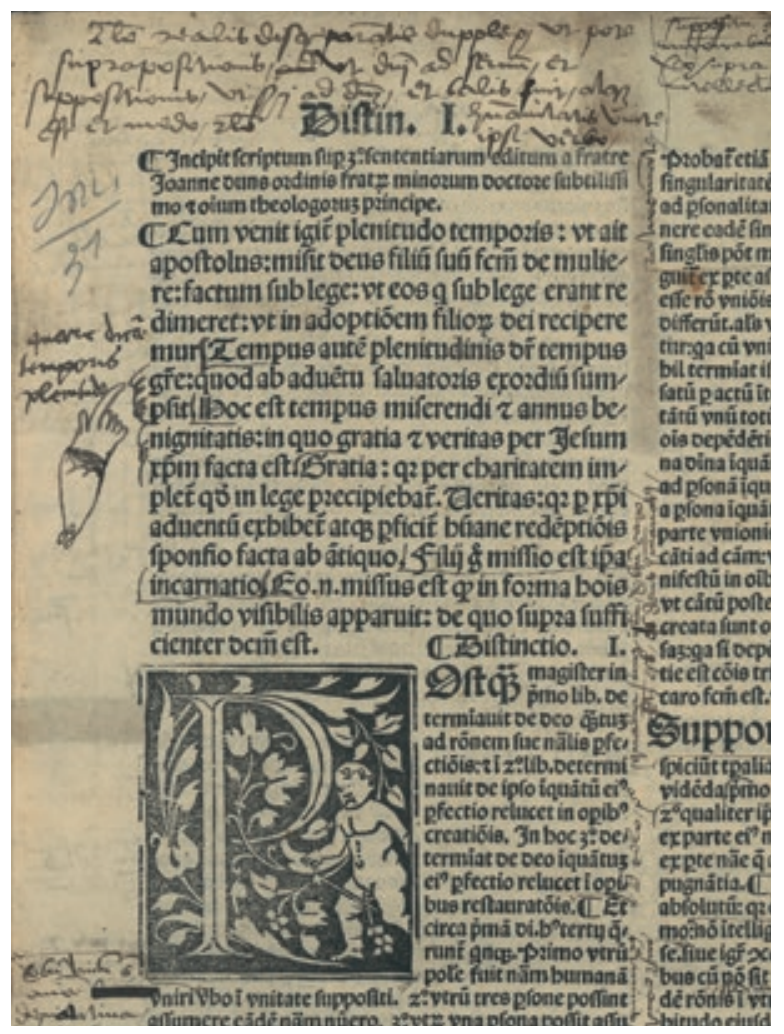

Jean Duns Scot, Quaestiones in quattuor libros sententiarum, Venise, Bonetus Locatellus pour Octavianus Scotus de Monza, [1496]

Commentaire des Quatre livres des sentences de Pierre Lombard, traité de théologie incontournable du $12^{\mathrm{e}}$ siècle qui fut commenté par les esprits les plus brillants pendant trois siècles. Annotations manuscrites sur la première page, dont une main pointant vers un passage précis (la future «manchette») et une lettrine imprimée « $\mathrm{P}$ (« Postquam ») avec un putto. 


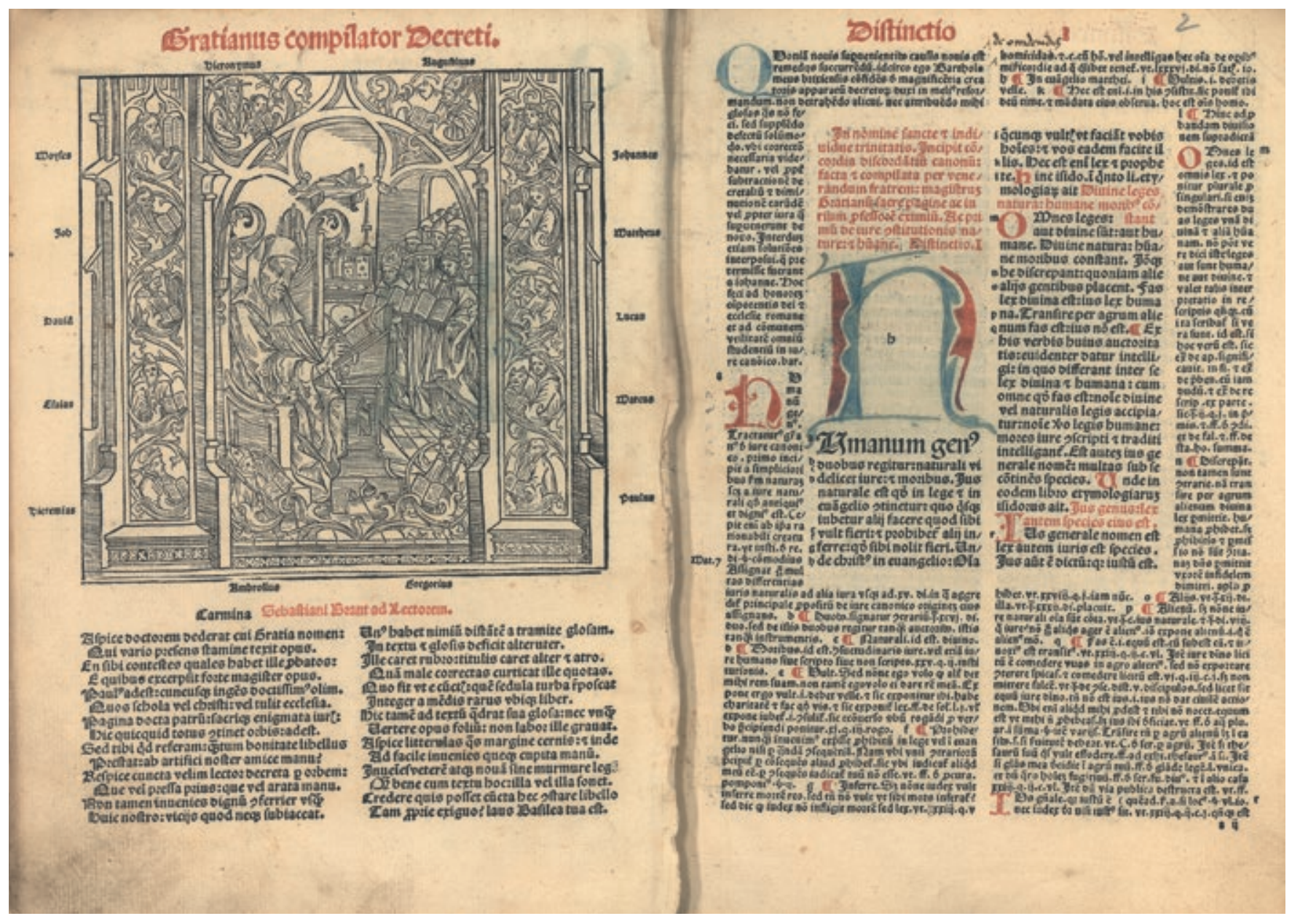

Le Décret de Gratien édité

par Sebastian Brant, Bâle, Froben, 1493

Édition prestigieuse du célèbre traité de droit canonique du moine Gratien (12 ${ }^{\mathrm{e}}$ siècle), imprimée en noir et rouge, s'ouvrant sur un poème dédicatoire de Sebastian Brant adressé au lecteur. La gravure du frontispice montre dans le compartiment du milieu, à gauche Gratien assis à son pupitre, à droite un collège d'ecclésiastiques, et dans les coins les bustes des quatre Pères de l'Église ; sur le bord gauche, les bustes de prophètes de l'Ancien Testament; sur celui de droite, ceux des quatre évangélistes et de saint Paul. Sur la page de droite figure une lettrine manuscrite «h» («humanum »).

Hermannus de Petra, Sermones quinquaginta super orationem dominicam [Lyon, Guillaume Balsarin, ca 1488]

Recueil de cinquante sermons sur le Notre Père. Lettrine introduisant le cinquantième sermon, avec un poisson jouxtant la lettre « $\mathrm{A}$ » (pour «Amen »).

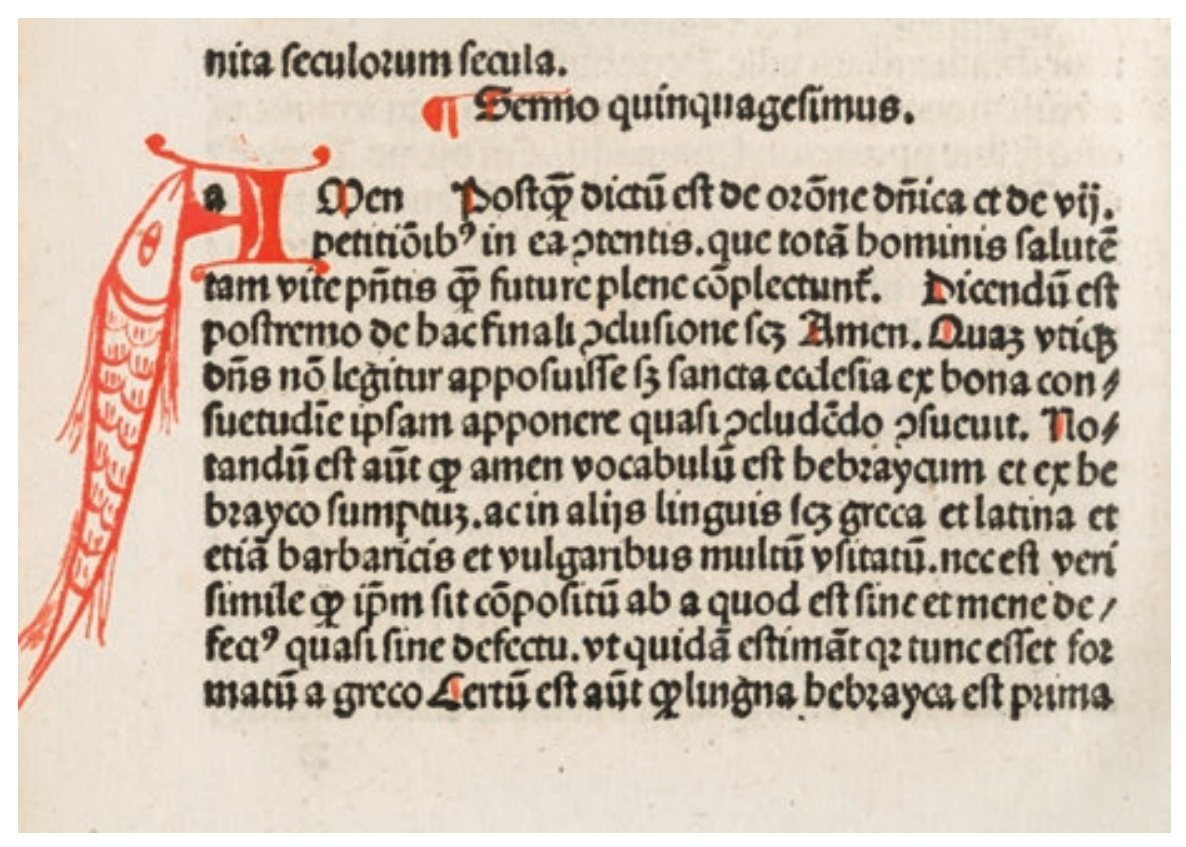

